\title{
A VISÃO PESSIMISTA DA MODERNIDADE: APONTAMENTOS SOBRE A CONCEPÇÃO DA MODERNIDADE EM MAX WEBER E GEORG SIMMEL
}

\author{
Marco Aurelio de Oliveira Leal ${ }^{1}$
}

\begin{abstract}
RESUMO: A modernidade é um tema central na sociologia e ocupa especial lugar no pensamento de autores clássicos, como Durkheim, Marx, Weber e Simmel. Focando na tradição alemã, Marx produz uma discussão acerca da modernidade diretamente ligada aos aspectos econômicos e industriais, ao apontar as mazelas promovidas por esse processo de avanço do capitalismo propriamente moderno, cujo efeito direto sobre a classe proletária representava o combustível necessário à revolução a ser empreendida por ela. Seus contemporâneos, Weber e Simmel, possuem uma visão particular acerca do fenômeno da modernidade. Apesar de produzirem em semelhante época, ambos os autores, ao tratarem deste fenômeno, vão ter visões com semelhanças e dissensos em suas discussões. Diferentemente de Marx, os dois autores possuem uma visão pessimista da modernidade que discutiremos ao longo deste breve artigo, destacando os seus pontos de confluência e dissonância, em especial as suas conclusões acerca dos conceitos da Jaula de Ferro e Tragédia da Cultura.
\end{abstract}

Palavras-chave: Weber; Simmel; Jaula de Ferro; Tragédia da Cultura; Modernidade.

\section{THE PESSIMIST VIEW OF MODERNITY: NOTES ON THE CONCEPTION OF MODERNITY IN MAX WEBER AND GEORG SIMMEL}

\begin{abstract}
Modernity is a central theme in sociology and occupies a special place in the thought of classical authors such as Durkheim, Marx, Weber and Simmel. Focusing on the German tradition, Marx produces a discussion about modernity directly linked to economic and industrial aspects, by pointing out the ills caused by this process of advancement of properly modern capitalism, whose direct effect on the proletarian class represented the necessary fuel for the revolution to be undertaken by her. His contemporaries, Weber and Simmel, have a particular view of the phenomenon of modernity. Despite producing at a similar time, both authors, when dealing with this phenomenon, will have views with similarities and disagreements in their discussions. Unlike Marx, both authors have a pessimistic view of modernity that we will discuss throughout this brief article, highlighting its points of confluence and dissonance, especially their conclusions about the concepts of the Iron Cage and Tragedy of Culture.
\end{abstract}

Keywords: Weber; Simmel; Iron Cage; Tragedy of Culture; Modernity.

\section{INTRODUÇÃO}

\footnotetext{
1 mestrando do Programa de Pós-Graduação em Sociologia da Universidade Federal de Pernambuco (PPGS-UFPE). Graduado em Ciências Sociais pela Universidade Federal de Pernambuco. E-mail: marco.leal.cs@gmail.com
} 
Revisitar os clássicos é sempre um desafio a ser enfrentado pelos sociólogos e sociólogas, em especial aos que se dedicam no refinamento e lapidação dos conceitos desenvolvidos, pelos chamados fundadores das ciências sociais, mas este é o papel da teoria social e dos que a praticam, olhar o dito e o não dito por esses autores, dando conta das contribuições e limitações que todo autor ou autora possui. Neste breve artigo investigaremos a questão da modernidade em Weber e Simmel, apontando em especial o pessimismo com relação a já dita modernidade presente em ambos.

Max Weber e Georg Simmel, ambos alemães e filhos de um mesmo tempo, possuem pontos de confluência em suas teorias acerca da modernidade e demais conceitos que estavam em voga naquele momento. Destaquemos a modernidade já que se trata de uma temática nodal para os fundadores canônicos da sociologia, além dos aqui tratados.

Weber desenvolverá uma longa teia de conceitos e preocupação metodológica notável para acessar a sua ideia de modernidade puramente racional, precisaremos, portanto, seguir o caminho metodológico de Weber para que possamos de modo producente, chegar aos seus argumentos passando pela religião, ao desencantamento do mundo, e por fim, a racionalidade. Mas sem deixar de lado toda a sua gama de conceitos e ferramentas analíticas que permitem uma compreensão de como o objeto da religião será tratado pelo autor, até chegarmos no pessimismo da jaula de ferro.

Já Simmel possui uma maneira diferente de praticar a sua ciência, sem uma conceituação tão precisa e sem uma metodologia tão engessada quanto a de Weber. Advinda de um processo histórico que o autor destaca ao distinguir cultura objetiva e subjetiva, sua ideia relacionada à tragédia da cultura nos remete à uma ideia de tragédia propriamente dita, intrínseca ao fenômeno da modernidade, tal qual a ideia de jaula de ferro em Weber.

Por fim, comparemos as duas concepções de modernidade dos autores elencados, destacando os seus pontos de encontro, em especial ao que está relacionado ao pessimismo sobre a modernidade em seus respectivos conceitos, que apesar de caminharem por chaves analíticas distintas e com metodologias também distintas, acabam chegando a pontos em comum.

\section{A CONCEPÇÃO WEBERIANA DE MODERNIDADE}


A modernidade para Max weber estaria diretamente ligada a um longo desencadear de processos que passam por um desencantamento do mundo até chegar numa sociedade puramente racional e burocrática. Essa sociedade aprisionaria os sujeitos no que o autor denominará “Jaula de Ferro". Para chegar as conclusões que postula Weber tentemos compreender a sua estrutura de pensamento, que envolve diversas camadas de rigorosa análise sociológica e histórica.

Se distanciou, segundo Giddens (2005), tanto do materialismo histórico ingênuo, que pensava na história como um reflexo das condições econômicas, como também se distancia do materialismo idealista de base hegeliana. Weber não endossava o discurso de divisão nas ciências entre o individual e o coletivo a partir de diferenças metodológicas. Para este autor, a metodologia tem como objetivo fazer a ciência, seja ela qual for. Progredir na construção do conhecimento e não ser fiel a um tipo de conhecimento ou metodologia já estabelecida, mas manter o rigor no método escolhido ou desenvolvido para a determinada análise.

Existe nas bases do pensamento weberiano um distanciamento entre as chamadas ciências naturais e as ciências sociais, que "estudam fenômenos "espirituais ou "ideais", que constituem características especificamente humanas, inexistentes no objeto temático das ciências naturais" (GIDDENS, 2005. p. 192). Contundo, mesmo se tratando de características que Weber denomina espirituais ou ideais, isso não implicaria na perda da objetividade científica das ciências sociais. O seu rigor metodológico, construído ao longo de suas diversas obras, demonstrará a sua preocupação com a questão do método científico. Nesse sentido haverá por sua parte uma preocupação em analisar cientificamente os fenômenos tal qual eles se apresentam e não como eles deveriam ser.

A compreensão metodológica do real vai passar por uma assimilação empírica e lógica por parte do pesquisador. Giddens ainda afirma que na concepção weberiana é impossível compreender todos os significados de um determinado fenômeno e nesse sentido vai mostrar o seu posicionamento contra uma ciência social geral. A cientista precisa estar atenta ao seu fenômeno e o que pretende analisar, pois não existe uma única realidade particular, mas múltiplas possibilidades de se investigar o objeto, recortando esses fenômenos para o que weber vai chamar de tipos ideais, "uma seleção operada a partir de uma infinidade da realidade (GIDDENS, 2005. p.197). 
O tipo ideal faz referência a uma construção mental da realidade pelo pesquisador ou pesquisadora, onde são selecionados um certo número de características, ou uma característica específica do objeto, a ser destacada e investigada na análise. Esse processo, segundo Weber, é uma tentativa de construir um tipo tangível para a análise, já que a realidade como advogada acima é infinita. Weber não se propõe em esgotar de possibilidades o objeto, mesmo que diversos cientistas se dediquem a uma investigação sobre semelhante fenômeno, ainda existirão possibilidades de pesquisas futuras acerca deste.

A ferramenta que representa o tipo ideal é uma tentativa de construir um corpo analítico para o objeto de estudo a partir de um número determinado de características. Um dos melhores exemplos da utilização do método weberiano dos tipos ideais é $O$ Homem Cordial (1939) de Sérgio Buarque de Holanda. Onde uma determinada propriedade, no caso a cordialidade é utilizada para analisar o desequilíbrio da ordem social brasileira e continuidade de uma estrutura patriarcal que se mantém na sociedade brasileira.

É importante destacar que o tipo ideal não é encontrado na sua forma pura dentro da sociedade, a característica recortada pela pesquisadora não necessariamente vai se reproduzir em si mesma. Ela é o fruto de uma seleção, o aguçamento de uma característica que permite a investigação e posteriormente a análise, não a reprodução da realidade, mas uma seleção, um recorte desta. "Assim, a interpretação e a explicação de uma configuração histórica exigem a construção de conceitos especificamente elaborados com esse propósito e que, tal como os objetivos da análise, não reflitam propriedades universalmente "essenciais" da realidade" (GIDDENS, 2005. p. 201). Esta será a principal ferramenta de Weber ao analisar principalmente os fundamentos da sociedade capitalista moderna.

Ainda no campo da metodologia weberiana caminhando além da sua base nos tipos ideais, destaquemos um dos seus tipos ideais mais importantes e essenciais para chegarmos à questão da modernidade racional elaborada por este, os tipos de ação, que ao lado dos tipos de dominação, caminham concomitantemente para a análise sociológica que o autor tratado propõe, 
(...) a sociologia interpretativa pode e deve basear-se em técnicas fixas de interpretação do significado, que podem assim ser comprovadas de acordo com os cânones convencionais do método científico. Segundo Weber, essas técnicas podem consistir na compreensão racional das relações lógicas que são parte constituinte do enquadramento subjetivo do agente, ou numa compreensão de tipo mais emotivo-simpático (GIDDENS,2005. p.207).

A ação ${ }^{2}$ será para weber um pilar da construção de uma explicação sociológica da realidade empírica, mas não se trata de qualquer ação, mas uma ação dotada de significado, tanto para o sujeito que a realiza, quanto para o outro sujeito, observador ou participante desta referida ação. A ação só será social quando houver o elemento subjetivo que ligue a ação ao seu significado. Como objeto da sociologia a ação é ricamente dotada de significados, ao citar Weber, Giddens advoga que "a ação ou conduta social (soziales Handein) é aquela que implica um significado subjetivo que se refere a outro indivíduo ou grupo" (GIDDENS, 2015. p. 206).

Fragmentando a ação em tipos ideais Weber desenvolve algumas ferramentas analíticas relacionadas a ele que é de bom tom que pontuemos, dada a sua preocupação com a metodologia e desenvolvimento dos conceitos, alguns já expostos aqui e outros que ainda estão por vir. Quatro tipos de ação são desenvolvidos por Weber para produzir ferramentas para a sua investigação.

\begin{abstract}
A ação social, como toda ação, pode ser determinada: 1) de modo racional referente a fins: por expectativas quanto ao comportamento de objetos do mundo externo e de outras pessoas utilizando essas expectativas como "condições" ou "meios" para alcançar fins próprios, ponderados e perseguidos racionalmente, como o sucesso; 2) de modo racional referente a valores: pela crença consciente no valor - ético, estético, religioso ou qualquer que seja sua interpretação absoluto e inerente a determinado comportamento como tal, independentemente do resultado; 3) de modo afetivo, especialmente emocional: por afetos ou estados emocionais atuais; 4) de modo tradicional: por costume arraigado (WEBER, 2000.p. 15).
\end{abstract}

Dos tipos de ação elencados, modifiquemos um pouco a linguagem do próprio Weber e destaquemos a ação racional ligada a fins e a ação social relacionada a valores, uma vez que ambos são destacados pelo próprio autor como próprios da modernidade,

\footnotetext{
${ }^{2}$ Importante destacar a diferença entre ação e comportamento. A ação só existe quando há um sentido subjetivo estabelecido pelo agente, já o comportamento pode representar qualquer atividade realizada pelo sujeito que não passa necessariamente pelo sentido subjetivo do sujeito. Já a ação social será aquela que além de ser dotada de sentido por quem a realiza é orientada para outro sujeito.
} 
pois estão ligados ao aspecto racional da vida. Já ou outros dois tipos a ação afetiva e a ação tradicional são destacadas por Weber como tipos de ação mais comuns em sociedades pré-modernas onde esses aspectos tradicionais e afetivos estavam em voga. No caso da contribuição do autor com sua canônica obra A Ética Protestante e o Espirito ${ }^{3}$ do Capitalismo (1904-1905), os tipos de ação social analisados serão justamente as ações sociais racionais movidas a fins e valores.

$\mathrm{Na}$ referida obra citada o autor deixa evidente desde o princípio a peculiaridade existente no seu objeto de análise, informando principalmente que não foram "apenas" os aspectos religiosos que forneceram as condições de existência do capitalismo moderno, mas, uma série de fatores estruturais que o formaram como tal. Contudo, o que chama a atenção de Weber é o caráter predominantemente protestante dos proprietários do capital, empresários e sujeitos dotados de maior qualificação para o trabalho (WEBER, 2004). A ideia de espírito, ou essência, servirá para Weber como ponto de partida para pensar a estrutura capitalista dentro de uma dinâmica propriamente cultural na modernidade.

Não é de nosso interesse fazer um desenvolvimento completo da referida obra de Weber, mas destacar os pontos principais que levam o seu argumento a pensar na ética de determinadas seitas protestantes como um ethos que servirá de base para um estilo de vida racional e voltado para o trabalho. Brevemente na ideia de vocação nos debruçando sobre a análise de Weber sobre Lutero. A revolução protestante será vista para Weber como a já falada base de um estilo de vida racional,

O "Racionalismo" é um conceito histórico que encerra um mundo de contradições, e teremos ocasião de investigar de que espírito nasceu essa forma concreta de pensamento e de vida "racionais" da qual resultam a ideia de vocação profissional e aquela dedicação de si ao trabalho profissional (WEBER, 2004.p. $69)$.

Com a reforma protestante promovida por Lutero houve uma virada na estrutura de conduta europeia, antes majoritariamente católica, um de seus principais aspectos está na saída de uma vida abnegada ligada diretamente aos valores católicos, para uma vida mundana, uma vez que na concepção do próprio Lutero não seria apenas após a morte

\footnotetext{
${ }^{3}$ No título original em alemão "Die protestantische Ethik und der 'Geist' des Kapitalismus" o termo 'Geist' utilizado por Weber está muito mais próximo da noção de essência do que a noção cristã que o termo 'espírito' pode trazer. 
que os sujeitos cumpririam a vontade de Deus, mas também no mundo e em especial no mundo do trabalho através de uma autorrealização moral. O dever e o cumprir a vontade de Deus, são desses dois aspectos que nasce a ideia de vocação profissional em Lutero, ainda limitada, pois o indivíduo deveria aceitar e submeter-se aos limites estabelecidos pela providência divina para a sua vida. "O indivíduo deve permanecer fundamentalmente na profissão e no estamento em que Deus o colocou e manter sua ambição terrena" (WEBER,2004. p. 77). As propostas de Lutero nesse sentido ainda estão presas às amarras do tradicionalismo, por esse motivo, Weber não o deslegitima, mas reconhece os seus limites, que acabaram por ser superados posteriormente pela vertente Calvinista do protestantismo, onde será possível identificar o espirito capitalista ${ }^{4}$, que não possui em sua análise parentesco com o Luteranismo.

O Calvinismo possui particularidades onde é possível observar o dito espirito capitalista, em princípio na chamada doutrina da predestinação, pela glória de Deus, alguns seres humanos já estariam predestinados a vida eterna, outros não (WEBER, 2004). O papel dos sujeitos no mundo terreno seria glorificar a deus, dentro do campo do trabalho que isso vai se tornar mais evidente. Na doutrina de Calvino o indivíduo já sabia internamente que foi escolhido por Deus, com o trabalho profissional, sem descanso, o sujeito conquistaria sua autoconfiança e afirmaria que a providência divina estava agindo na sua vida, mostrando ser um dos eleitos.

Aqui repousa a ideia de desencantamento do mundo, a eliminação da magia como meio de salvação, seria a partir do trabalho ascético, realizando a vocação designada por Deus na vida do sujeito que este alcançaria os desígnios da providência. O modelo de uma vida puramente racional, voltada para o trabalho ascético é a grande contribuição de Weber, que faz um paralelo entre esse estilo de vida ascético com a sociedade moderna que se engendrava. Era necessário que as ações dos indivíduos eleitos fossem vistas pelo restante do mundo mostrando o seu estado de graça, o que dentro do mundo do trabalho em formação e divisão social do trabalho mostra uma sistemática conformação racional da vida, "não o trabalho em si, mas o trabalho profissional racional, é isso exatamente que Deus exige" (WEBER, 2004.p. 147).

\footnotetext{
${ }^{4}$ Weber consegue identificar esse aspecto em diversas outras seitas protestantes, como Petistas e Anabatistas, mas é dentro do Calvinismo que o espirito do capitalismo aparecerá de modo mais evidente. 
Esse será o argumento defendido por Weber até o fim de sua obra, que apesar de trabalhar com um recorte bem estabelecido desde o princípio, investigar de que forma a ética de determinadas seitas protestantes acabou por influenciar o desenvolver do capitalismo propriamente moderno. A racionalização da vida em sua forma ascética e voltada para o trabalho intramundano que teve seu princípio com as viradas trazidas em princípio com a Revolução Protestante e as seitas que vieram posteriormente transformaram as estruturas da sociedade a tornar-se o que conhecemos como sociedade moderna, a partir das relações entre o protestantismo ascético e a vida econômica cotidiana.

A ascese protestante intramundana também precisa ser analisada sobre o ponto de vista do acúmulo de riquezas, quanto mais se tinha, mais evidente seria a graça de Deus na vida daquele sujeito, se tornaria mais evidente a sua salvação e a benção que este possuía por ser um dos eleitos. O gozo dessas riquezas não era condenado, o gozo condenável era o consumo de luxo e ostensivo, "em compensação, teve o efeito [psicológico] de liberar o enriquecimento dos entraves da ética tradicionalista, rompeu as barreiras que cerceavam a ambição de lucro, não só ao legalizá-lo, mas também ao encarálo (no sentido descrito) como diretamente querido por Deus" (WEBER, 2004.p. 155).

A especialização das funções dentro das profissões numa dinâmica ascética é essencial dentro de todo esse processo, a profissão fixa garante um certo caráter sistemático à vida dos sujeitos, sistematicidade metódica que é essencial para a ascese intramundana, "assim como o aguçamento da significação ascética da profissão estável, devido ao desencantamento do mundo, transfigura eticamente o moderno tipo de homem especializado, assim também a interpretação providencialista das oportunidades de lucro transfigura o homem de negócios" (WEBER, 2004. p. 149). A exposição de todo esse argumento lógico da contribuição weberiana foi necessário diante de sua preocupação metodológica e do desenvolvimento de conceitos necessários chegarmos no argumento da vida racional, base da modernidade para Weber.

O estilo de vida ascético acabou por desenvolver esse ethos profissional, rompendo as fronteiras da própria religião protestante, se inserindo nas bases do desenvolvimento da sociedade capitalista. Os indivíduos já nascem nessa engrenagem, nesse estilo de vida onde não há escapatória, uma vez que a própria ascese permitia a exploração de um sujeito pelo outro em busca de lucros, opressão disfarçada de vocação 
profissional por parte dos empresários, por exemplo. Esses pontos, recortados por Weber, mostram além do seu rigor metodológico e teórico um pessimismo latente com relação a própria modernidade. $\mathrm{O}$ estilo de vida racional e capitalista coloca os indivíduos no que o autor chama de "rija crosta" termo traduzido por Parsons ${ }^{5}$ como a Jaula de Ferro, uma estrutura tão poderosa que se edificou ao longo da história e da qual não é possível escapar e que "determina com pressão avassaladora o estilo de vida de todos os indivíduos que nascem dentro dessa engrenagem" (WEBER, 2004.p. 165).

Essa é a modernidade desenhada por Weber, uma sociedade moderna, capitalista e ceifadora dos sujeitos. Essa modernidade se apresenta de modo tão engessado na tradição weberiana que de fato parece ser impossível sair da assim chamada Jaula de Ferro, que construída ao longo da história e imersa nesse ethos para uma vida ascética e voltada para o trabalho, não permite uma possibilidade de escapismo. "No que a ascese se pôs a transformar o mundo e a produzir no mundo os seus efeitos, os bens exteriores deste mundo ganharam poder crescente e por fim irresistível sobre os seres humanos como nunca antes na história" (WEBER, 2004. p. 165). Nesse sentido a racionalidade capitalista é vitoriosa apoiada em diversas bases mecânicas que estruturam a vida tal qual ela é. O dever profissional, de base ascética, falseia as relações de dominação, mais uma vez Weber não nos dá possibilidades de escapar de estrutura tão rígida.

\section{A CONCEPÇÃO SIMMELIANA DE MODERNIDADE}

Georg Simmel, nascido em Berlim no ano de 1858, foi um grande intelectual multidisciplinar de sua época, transitava pela filosofia, sociologia, economia, política, história e antropologia. Esse passear pelas áreas que fazia Simmel foi um dos grandes entraves para a sua participação do grande cânone da sociologia, até os dias de hoje, raramente ele está inserido nos pais fundadores, que continuam sendo três. Contudo, a contribuição de Simmel, ao lado por exemplo, das de Weber são essenciais para a compreensão do fenômeno da modernidade.

Apesar de frequentarem os mesmos pontos de discussão e o compartilharem a sua época de produção, Weber e Simmel possuem diferentes posicionamentos acerca da

\footnotetext{
${ }^{5}$ Foi o responsável pela tradução para o inglês da referida obra, traduzindo os termos utilizados por Weber como iron cage. 
sociedade moderna, que encontram pontos de encontro, apesar dos caminhos diferentes traçados pelos autores. Simmel era um ensaísta, mudava não apenas de objeto com frequência, mas também do ponto de vista desse objeto. Tentando compreender o multiverso de possibilidades que podem permear uma determinada questão. A preocupação conceitual e metodológica quase engessada que nos apresenta Weber não encontra lugar na tradição simmeliana, portanto, não temos a mesma necessidade de traçar uma longa discussão sobre a sua concepção da modernidade, conceitos existem evidentemente, mas de forma densa como na contribuição de Weber. Destaquemos os aspectos da modernidade como evidenciados por Simmel, elencando elementos de pessimismo também presentes nos seus escritos.

O autor produziu uma sociologia formal, também conhecida como uma sociologia das formas sociais, influenciado pela filosofia kantiana, ${ }^{6}$ que distinguia a forma do conteúdo dos objetos de estudo do conhecimento humano. Tal distinção almejava elucidar o entendimento da vida social já que no processo de sociação "Vergesellschaftung" o invariante eram as formas em que os indivíduos se agregavam e não os indivíduos em si. O indivíduo passaria sua vida buscando uma individualidade, mas essa possibilidade é limitada pelos próprios invariantes culturais. A forma se estabelece abstraindo o conteúdo, se tornando algo necessariamente formal. Já o conteúdo, que também podemos chamar de vida só pode se estabelecer na singularidade dos sujeitos.

\begin{abstract}
A tendência moderna de diferenciação chega assim a um ponto tal que desmente sua primeira forma, sem que essa contraposição gere equívocos a respeito da identidade do impulso fundamental. Este atravessa toda a modernidade, permanecendo o mesmo: o indivíduo busca a si mesmo como se ainda não se possuísse, e ainda assim está seguro de ter em seu eu o único ponto sólido (SIMMEL, 2006. p.111).
\end{abstract}

Tomando o dinheiro como o ponto de partida da modernidade, o autor acaba por estabelecer que a modernidade está intimamente ligada a vida monetária, "assim que o dinheiro se torna a medida de todas as outras coisas - uma infinidade de objetos extremamente diferentes podendo se obter em troca dele - ele mostra uma ausência de cor e qualidade que, em certo sentido desvaloriza tudo aquilo que dele é equivalente"

\footnotetext{
${ }^{6} \mathrm{O}$ neokantismo era uma de pensamento em voga na Alemanha da época, também tendo influenciado a produção de Weber.
} 
(SIMMEL, 1993. p. 5). Não há na visão simmeliana uma sociedade física, mas um conjunto de processos que engendram a sociedade tal como a encontramos, desenvolvida a partir da interação, fatores próprios da vida moderna. Tal modernidade possui um caráter ambivalente, do mesmo modo que liberta, também acaba por limitar os sujeitos em uma constante busca por individualização no mundo moderno "A generalidade da natureza humana atenua e torna suportável o isolamento dos indivíduos. Ela também torna a liberdade eticamente possível, à medida que parece cortar pela raiz a consequência inevitável da liberdade, a saber, o desenvolvimento da desigualdade" (SIMMEL, 2006. p. 98).

O mesmo processo de divisão do trabalho social, liberta, mas também aliena nos sujeitos que se veem imersos no mundo cultural automatizado e essa engrenagem automática está cada vez mais presente na vida cotidiana como advoga Simmel. A cultura dos sujeitos engendra a sua participação no mundo e para o mundo, no mesmo momento em que se coloca também se constitui a partir dela, numa perspectiva dúbia, subjetiva, mas também objetiva, "arte e moral, ciência e objetos conformes a fins, religião e direito, técnica e normas sociais - são estações pelas quais o sujeito tem de passar para adquirir esse valor específico que é sua cultura" (SIMMEL, 2014. p. 147), a partir de uma configuração irrestritamente histórica, a cultura será em sua análise uma síntese.

Façamos uma distinção entre cultura objetiva e cultura subjetiva, já que a cultura possui em sua tradição um papel fundamental para o autor. A cultura subjetiva se constitui no processo de interação entre os sujeitos e devido a sua liberdade permite a diferenciação entre estes, em especial no locus urbano, segundo o autor, ambiente propício para a modernidade. A diferenciação entre os sujeitos está intimamente ligada à individualidade predisposta dentro de uma possível esfera de liberdade individual acessada fora da subjetividade do sujeito,

Na medida em que essas avaliações do espírito subjetivo e do espírito objetivo estejam em oposição, a cultura conduz sua unidade através de ambas: pois ela significa aquela maneira de realização individual que só pode se efetuar no acolhimento ou utilização de uma configuração suprapessoal que, em qualquer sentido, está fora do sujeito (SIMMEL, 2014. p. 151).

Contudo, dentro do processo de modernização está a cultura objetiva, por sua vez, ligada diretamente à divisão do trabalho social. É no mundo do trabalho que ela irá se 
disseminar. Os sujeitos na sociedade moderna e capitalista estão cada vez mais inseridos na lógica objetiva, que acaba por objetivar esses sujeitos, que não identificam essa objetivação.

Se esse espírito objetivo da sociedade histórica constitui o conteúdo cultural desta no sentido mais amplo, então a significação prática da cultura de cada um de seus elementos se mede, não obstante, pela proporção na qual eles se tornam momento de desenvolvimento dos indivíduos (SIMMEL, 2005. p. 50).

Ao absorver a cultura objetiva e tratando-a como subjetiva, as relações de dominação, que para Simmel estão diretamente ligadas as dinâmicas culturais, se falseiam como um elemento que naturaliza a dominação. Ocorre, portanto, uma objetificação dos sujeitos e ainda uma dessubjetivação dos próprios sujeitos, "essa realização a partir de si mesma, mas somente através daquelas configurações agora totalmente estranhas e cristalizadas em uma unidade fechada em si mesma" (SIMMEL, 2014.p. 147). A dualidade da estrutura subjetiva-objetiva por si já configura na análise do autor uma tragédia. A tragédia da cultura, conceito chave sobre a modernidade, coloca à mostra $\mathrm{o}$ processo acima já destacado onde os sujeitos se tornam formadores do que produzem, mas estranhando o processo. Nesse sentido Simmel retoma e reformula as ideias de fetichismo e estranhamento propostas por Marx, elevando essas categorias ao campo da construção histórica da cultura e não apenas da evolução histórica relacionada ao campo econômico.

\footnotetext{
Pertence ao conceito de toda cultura o fato de o espírito criar algo objetivo independente por onde passa o desenvolvimento do sujeito de si para si mesmo; mas por isso mesmo este elemento integrador que condiciona a cultura é predeterminado por um desenvolvimento específico, que sempre consome as forças do sujeito (SIMMEL, 2014. p.160).
}

Simmel acredita que essas dinâmicas constituem uma relação dúbia de dominação nas esferas da cultura e podem ser encontradas em múltiplos objetos, desde a urbanização, o consumo e a vida mental. A tragédia da cultura, que compararemos à jaula de ferro weberiana também revela o caráter pessimista da modernidade desenvolvida por esses autores alemães em sua época de produção. 


\section{ENTRE A JAULA DE FERRO E A TRAGÉDIA DA CULTURA}

Diferente de Weber, alçado a um alto cânone da sociologia, Simmel não alcançou tal reconhecimento em seu tempo de produção, sendo muitas vezes deslegitimado, em parte pelo seu caráter ensaístico, diferentemente do trabalho rigorosamente metodológico produzido por Weber em suas obras. Entretanto, a concepção da modernidade de ambos encontra um ponto de confluência no pessimismo acerca da sociedade advinda do processo histórico de modernização da vida dos sujeitos. Nessa semelhança repousa a congruência entre as suas conclusões sobre o que seria a jaula de ferro e a tragédia da cultura, respectivamente desenvolvidas por Weber e Simmel.

O pessimismo de Weber não nos deixa escapatória. Ao analisar o processo histórico que configura a sociedade como propriamente racional, os sujeitos nela inseridos não conseguem escapar devido as próprias estruturas profundas que fundam a sociedade moderna como tal. A Jaula de Ferro serve bem à essa ideia de que não há como fugir de uma estrutura tão racional engendrada pelos sujeitos. Uma sociedade extremamente burocratizada e fechada a todos os indivíduos que nascessem dentro dessa dinâmica social que os antecedeu.

Simmel vai pelo caminho das transformações das dinâmicas culturais dentro da divisão do trabalho social, observando a sociedade moderna como uma sociedade onde o sujeito vive em uma dinâmica objetificada. Num complexo engendrar entre a objetividade e a subjetividade também repousa o pessimismo de Simmel, pois mesmo na infinitude de possibilidades dada pela modernidade o sujeito ainda estaria preso às dinâmicas culturais que o antecederam, a tragédia da cultura, formada pelo jogo objetividade-subjetividade, também limita os sujeitos de maneira semelhante à jaula de ferro weberiana.

Nesse sentido, à guisa de uma conclusão, podemos estabelecer que mesmo com caminhos teóricos e metodológicos distintos, Weber e Simmel seguem a estrada do pessimismo e do estabelecimento do capitalismo relacionado a uma dinâmica cultural propriamente moderna que lhe dota de sentido. Ainda seguindo o norte histórico que imbui de sentido a cultura moderna, a relevância do pessimismo para o pensamento sociológico não se esgota nas elaborações destes autores, pelo contrário, este influenciará autores contemporâneos como Benjamin, Adorno, Horkheimer, Mannheim e o próprio Parsons, em suas análises acerca dos fenômenos sociais tratados posteriormente. 


\section{REFERÊNCIAS BIBLIOGRÁFICAS}

GIDDENS, Anthony. Capitalismo e moderna teoria social. Queluz de Baixo: Presença, 2005.

SIMMEL, Georg. O conceito e a tragédia da cultura, de Georg Simmel. SANTOS, Antonio Carlos (Tradutor). Crítica Cultural, Palhoça, v. 9, n. 1, p. 145-162, jan./jun. 2014.

SIMMEL, Georg. Filosofia do amor. São Paulo, Martins Fontes, 1993.

. "A Divisão do trabalho como causa da diferenciação da cultura subjetiva e objetiva”. In: Jessé Souza e Berthold Oelze (orgs), Simmel e a Modernidade. Brasilia: ed. UNB, 2005.

- Questões fundamentais da sociologia: indivíduo e sociedade. Rio de Janeiro: Jorge Zahar Ed., 2006.

WEBER, Max. Economia e Sociedade. Vol.1. Brasília: ed. UNB, 2000.

das letras, 2004.

A ética protestante e o espirito do capitalismo. São Paulo: Companhia 